\title{
The Sinorhizobium (Ensifer) fredii HH103 Type 3 Secretion System Suppresses Early Defense Responses to Effectively Nodulate Soybean
}

\author{
Irene Jiménez-Guerrero, ${ }^{1}$ Francisco Pérez-Montaño, ${ }^{1}$ José Antonio Monreal, ${ }^{2}$ Gail M. Preston, ${ }^{3}$ \\ Helen Fones, ${ }^{3}$ Blanca Vioque, ${ }^{4}$ Francisco Javier Ollero, ${ }^{1}$ and Francisco Javier López-Baena ${ }^{1}$ \\ ${ }^{1}$ Departamento de Microbiología, and ${ }^{2}$ Departamento de Fisiología Vegetal, Facultad de Biología, Universidad de Sevilla, Avda. \\ Reina Mercedes, 6, 41012, Sevilla, Spain; ${ }^{3}$ Department of Plant Sciences, University of Oxford, OX1 3RB, Oxford, United \\ Kingdom; and ${ }^{4}$ Departamento de Fitoquímica de Alimentos, Instituto de la Grasa (CSIC), Avda. Padre García Tejero, 4, 41012, \\ Sevilla, Spain
}

Submitted 26 February 2015. Accepted 8 March 2015.

\begin{abstract}
Plants that interact with pathogenic bacteria in their natural environments have developed barriers to block or contain the infection. Phytopathogenic bacteria have evolved mechanisms to subvert these defenses and promote infection. Thus, the type 3 secretion system (T3SS) delivers bacterial effectors directly into the plant cells to alter host signaling and suppress defenses, providing an appropriate environment for bacterial multiplication. Some rhizobial strains possess a symbiotic T3SS that seems to be involved in the suppression of host defenses to promote nodulation and determine the host range. In this work, we show that the inactivation of the Sinorhizobium (Ensifer) fredii HH103 T3SS negatively affects soybean nodulation in the early stages of the symbiotic process, which is associated with a reduction of the expression of early nodulation genes. This symbiotic phenotype could be the consequence of the bacterial triggering of soybean defense responses associated with the production of salicylic acid (SA) and the impairment of the T3SS mutant to suppress these responses. Interestingly, the early induction of the transcription of GmMPK4, which negatively regulates $\mathrm{SA}$ accumulation and defense responses in soybean via WRKY33, could be associated with the differential defense responses induced by the parental and the T3SS mutant strain.
\end{abstract}

Nitrogen-fixing rhizobia induce the formation of nodules on the roots and stems of legumes. Within these structures, they differentiate into bacteroids that fix atmospheric nitrogen into ammonia, which is used by the plant. In exchange, the legume provides an appropriate environment for bacterial growth. In response to inducer plant flavonoids, rhizobia synthesize specific signal molecules called Nod factors (NF), which are responsible for nodule initiation and development. However, there are other molecules such as surface polysaccharides and proteins secreted by bacterial secretion systems that also seem to play a very important role in the establishment of an efficient symbiosis with the host plant (Downie 2010).

Corresponding author: F. J. López-Baena: Telephone: +34 954554330; Fax: +34 954557830; E-mail: jlopez@us.es

*The $\boldsymbol{e}$-Xtra logo stands for "electronic extra" and indicates that one supplementary figure and three supplementary tables are published online.

(C) 2015 The American Phytopathological Society
Plants use different mechanisms to combat pathogens. Thus, in the basal defense response, conserved microbial microbeassociated molecular patterns (MAMP) are recognized by specific plant extracellular receptors, which results in the MAMP-triggered immunity (MTI) response. Many phytopathogenic gram-negative bacteria use a highly specialized secretion system, called the type 3 secretion system (T3SS), to deliver effector proteins directly into the host cells. These effectors can alter host signaling and suppress plant defenses, providing a beneficial environment for bacterial multiplication (effector-triggered susceptibility) (Alfano and Collmer 2004; Jones and Dangl 2006). However, the effectors can also be recognized by specific plant resistance $(\mathrm{R})$ proteins and induce strong defense responses, frequently associated with a localized hypersensitive response (HR), to block infection (effectortriggered immunity [ETI]). Interestingly, some effectors are also able to suppress ETI responses, suggesting that they may have multiple targets or target shared components between MTI and ETI (Boller and Felix 2009; Tsuda and Katagiri 2010).

Activation of mitogen-activated protein kinases (MAPK) is one of the earliest signaling events after plant recognition of MAMP and effectors, and this activation is involved in signaling multiple defense responses. Pathogens employ effectors to suppress MAPK activation and downstream defense responses to promote pathogenesis (Meng and Zhang 2013). In soybean, MPK4 negatively regulates defense responses and positively regulates growth and development, and MPK6 functions as both repressor and activator in defense responses (Liu et al. 2011, 2014).

Plant hormones are also involved in plant defense responses. The three major phytohormones responsible for mediating responses to pathogens are jasmonic acid (JA), ethylene (ET), and salicylic acid (SA) (Kunkel and Brooks 2002). Other hormones, such as abscisic acid (ABA), a hormone normally related to responses to abiotic stresses, has been recently associated with the fine-tuned regulation of defenses (Pieterse et al. 2009).

Sinorhizobium (Ensifer) fredii HH103 (hereafter HH103) is a broad-host-range bacterium that nodulates many legumes, including soybean, which is considered its natural host plant (Margaret et al. 2011). Like phytopathogens, HH103 secretes effectors, called Nops, through a symbiotic T3SS (de Lyra et al. 2006). The specific functions of the rhizobial effectors in nodulation are still unknown, although some of them have been biochemically characterized and affect nodulation in a host-dependent 
manner (Deakin and Broughton 2009; Okazaki et al. 2010; Sánchez et al. 2012; Tsukui et al. 2013; Xin et al. 2012).

Although there is a lot of information about plant defenses in response to a pathogenic attack, little is known about the defense responses triggered in legumes upon infection with compatible rhizobia. The symbiotic process resembles a pathogenic interaction in that the host plant is chronically infected and rhizobia need to suppress the defense mechanisms to colonize plant tissues and maintain a successful symbiotic interaction. It has been proposed that, in the initial steps of nodulation, rhizobia could be recognized by plant receptors and elicit a weak, local, and transitory MTI response that is subsequently suppressed by several mechanisms, including extracellular polysaccharides and NF (Zamioudis and Pieterse 2012). Other authors, such as Vasse et al. (1993), have shown that compatible rhizobia induce a localized HR response in the host plant that could play a key role in the regulation of nodule number. In this sense, López-Baena et al. (2009) showed that, in the symbiosis HH103-soybean, mutants unable to secrete Nops induce the expression of the pathogenesis-related (PR) protein PR1 in soybean roots and leaves, suggesting that the effectors could be suppressing systemic soybean defense responses and, therefore, promoting infection. It is remarkable that there are several soybean genotypes, including $R j 2, R j 3, R j 4$, and $R f g 1$ (allelic to $R j 2$ ), which restrict nodulation with specific rhizobial strains. In some cases, this impairment is mediated by T3SS effectors (Hayashi et al. 2012; Yang et al. 2010). For instance, Bradyrhizobium elkanii USDA122 and some S. fredii strains are unable to nodulate 'Hardee' soybean $(R j 2)$ or American soybean varieties $(R f g 1)$, respectively (Meinhardt et al. 1993; Tsukui et al. 2013).

There is currently a lack of information about soybean defense responses that limit the number of infection events and control rhizobial growth, and also about mechanisms such as the T3SS that have evolved to induce or suppress these defenses to block or promote nodulation, respectively; influence symbiotic competitiveness; or modulate the nodulation range. In this work, soybean responses to inoculation with HH103 and a mutant derivative defective in type 3 secretion were studied to identify the overall effect of the HH103 T3SS in the establishment of an effective symbiosis.

\section{RESULTS}

\section{The absence of the $S$. fredii HH103 T3SS causes a delay in soybean nodule formation and a reduction in the expression of the early symbiosis genes GmNIN and GmENOD40.}

Our previous results showed that an $\mathrm{HH} 103$ mutant defective in the ttsI gene was unable to secrete Nops and displayed a significant reduction in its ability to form nodules in soybean. In addition, both the parental strain and the mutant derivative $t t s I \Omega$ induced GmPRI gene expression early in the infection process. However, GmPR1 gene expression was much stronger in plants inoculated with the mutant strain (López-Baena et al. 2008, 2009). To elucidate whether this early defense response was associated with a reduction or delay in the formation of nodules in the initial stages of the symbiosis, the kinetics of nodulation of 'Williams 82' soybean plants inoculated with $\mathrm{HH} 103$, the $t$ tsI $\Omega$ mutant strain, and the mutant complemented with a plasmid carrying the nod box previous to ttsI and the operon formed by ttsI, rhcC2, and $y 4 x K$ (López-Baena et al. $2008,2009)$, was studied. Nodules were counted at 8, 12, 16, 24 , and 30 days after inoculation (dai). Results obtained showed that the number of nodules formed were significantly higher in plants inoculated with HH103 in all the time points analyzed in comparison with plants inoculated with the mutant strain. In addition, nodules could only be detected at 12 dai in plants inoculated with the $t t s I \Omega$ mutant in contrast to plants inoculated with the parental strain, in which nodules were detected at 8 dai (Fig. 1A). Therefore, the first 8 days after inoculation were selected as the time interval to further study soybean defense responses. Interestingly, growth of the main root was aborted in plants inoculated with the mutant strain (Fig. 1B). Complementation of the mutation restored the capacity to nodulate soybean as the parental strain and the interruption in the growth of the main root was not observed (Fig. $1 \mathrm{~A}$ and $\mathrm{B}$ ).

The expression of both NIN and ENOD4O genes is induced early after NF recognition and is associated with the formation of infection threads and nodules, respectively (Geurts et al. 2005; Marsh et al. 2007). To determine whether the inactivation of the T3SS correlated with lower expressions of early nodulation genes, the expression of GmNINa, GmNINb, and GmENOD40.2 was quantified at 2, 4, and 8 dai. The rhizobial strains described previously were used to inoculate soybean plants. Thus, the expression of the NIN genes was significantly higher in the roots of plants inoculated with the parental strain than in plants inoculated with the tts $\Omega$ mutant during the whole time-course assay. In addition, transcription of the NIN genes decreased with time, reaching a maximum at 2 dai and obtaining the lowest values at 8 dai (Fig. 1C). In the case of the ENOD40.2 gene, a peak of expression was observed at 4 dai (64-fold) in plants inoculated with $\mathrm{HH} 103$ and then declined. Transcription levels of this gene did not significantly change with time in plants inoculated with the mutant strain (approximately 20 -fold). This expression was always similar to that observed in plants inoculated with the parental strain, with the exception of 4 dai, in which the expression was significantly lower (Fig. 1C).

\section{The $S$. fredii HH103 T3SS modulates SA concentration in soybean roots early in the symbiotic process.}

Many plant pathogens use the T3SS to alter the host hormonal balance for their own benefit (Grant and Jones 2009), and our previous data showed increases in the expression of the SA-dependent gene GmPRl in soybean roots in the absence of nodulation outer proteins (López-Baena et al. 2009). Therefore, SA concentration was quantified to determine whether the HH103 T3SS could modulate the production of this plant hormone.

The SA present in soybean roots was initially determined in a high-throughput assay using the SA biosensor strain Acinetobacter sp. ADP1_lux (Huang et al. 2006) at 2, 4, and 8 dai. A significant increase in SA production in roots of plants inoculated with the $t t s I \Omega$ mutant strain was observed at all time points analyzed and also in leaves at 8 dai (Fig. 2A). In order to validate the method, SA was also quantified by high-performance liquid chromatography (HPLC). In this case, a new time point for hormone quantification ( $2 \mathrm{~h}$ after inoculation [hai]) was included to study immediate plant responses to the presence of rhizobia. When comparing SA quantifications using the biosensor and the results obtained by HPLC, similar results were observed in all the treatments assayed. However, the estimated levels of SA detected were always lower when using the biosensor, taking into consideration (among other possible factors) that the method using the biosensor employs fresh mass and not lyophilized tissues. The HPLC quantification showed that, during almost the whole experiment, the concentration of SA in plant roots was significantly higher in plants inoculated with the mutant strain than in those inoculated with HH103. However, at 2 hai, the concentration of SA in plants inoculated with $\mathrm{HH} 103$ was higher (Fig. 2B). In control plants and in plants inoculated by HH103, SA concentration decreased with time, with a reduction of approximately 
A

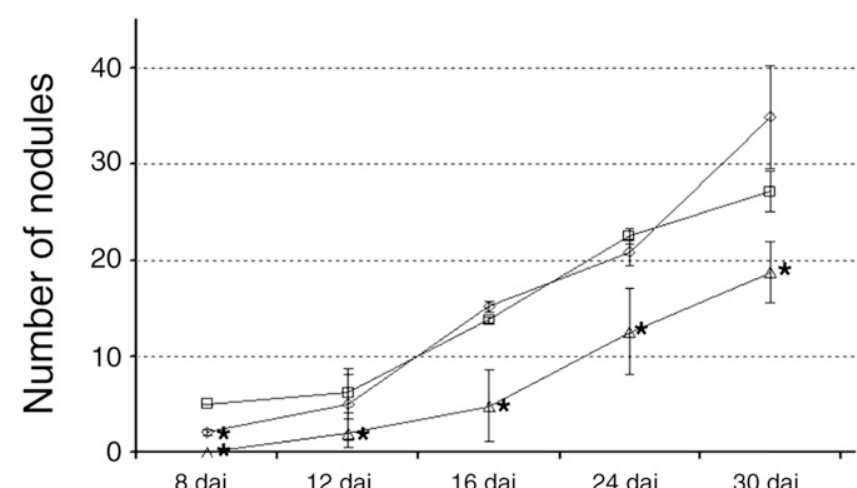

है
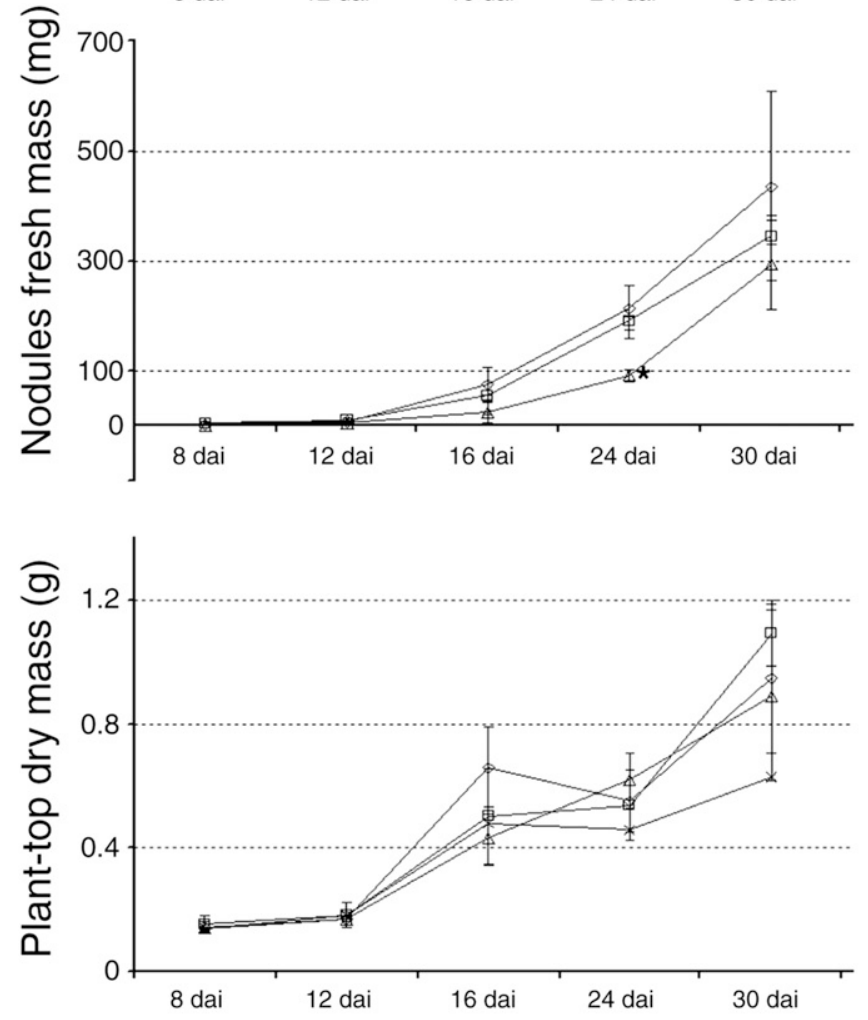

B

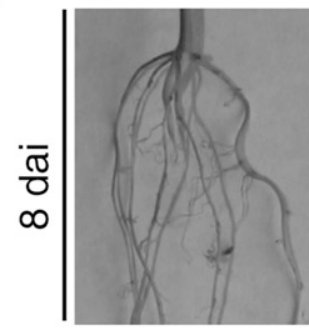

Uninoculated

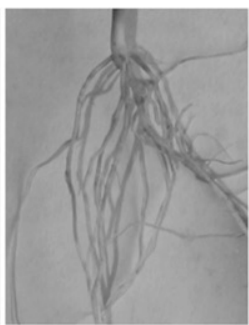

HH103 Rif

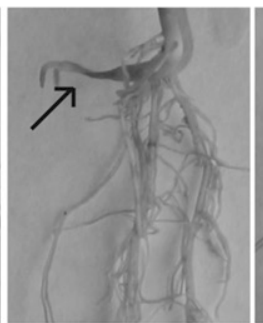

HH103 Rif
C
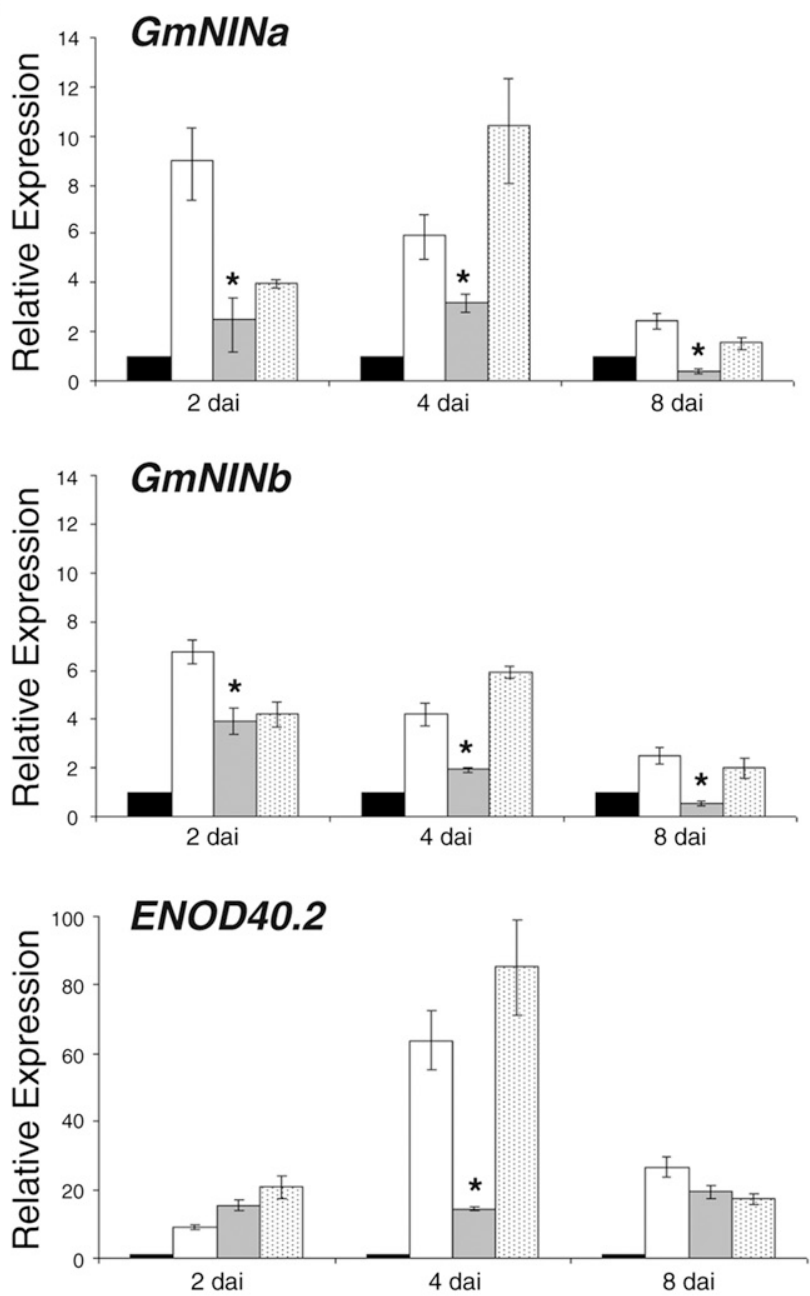

Fig. 1. A, Kinetics of nodulation of soybean plants inoculated with HH103 Rif $^{\mathrm{R}}$ (squares), HH103 Rif $^{\mathrm{R}} t t s I \Omega$ (triangles), and HH103 Rif ${ }^{\mathrm{R}} t$ tsI $\Omega$ complemented (diamonds). Crosses indicate uninoculated control plants. Data represent the mean \pm standard deviation (SD) of the mean for four Leonard jars containing two soybean plants $(n=8)$. The experiment was performed twice obtaining similar results. B, Growth abortion of the main root caused by the inoculation with a HH103 T3SS mutant strain. Sample images of soybean roots from plants grown in vermiculite. The arrow indicates growth abortion of the main root; dai = days after inoculation C, Time-course analysis of the expression of the GmNINa, GmNINb, and GmENOD40.2 genes in soybean roots. Plants were inoculated with HH103 Rif ${ }^{\mathrm{R}}$ (white bars), HH103 Rif $^{\mathrm{R}} t t s I \Omega$ (gray bars), and HH103 Rif $^{\mathrm{R}}$ ttsI $\Omega$ complemented (dotted bars). Samples from two independent biological replicates were collected. Data shown are the mean $\pm \mathrm{SD}$ of the mean for two quantitative polymerase chain reactions performed in triplicate for each biological replicate. Expression is calculated relative to uninoculated control plants (black bars). For A and C, mutant HH103 Rif ${ }^{\mathrm{R}}$ ttsI $\Omega$ was individually compared with the parental strain $\mathrm{HH} 103 \mathrm{Rif}^{\mathrm{R}}$ by using the Mann-Whitney nonparametric test. Asterisks indicate that numbers are significantly different at the level $\alpha=5 \%$ $(P<0.05)$. 


\section{A}

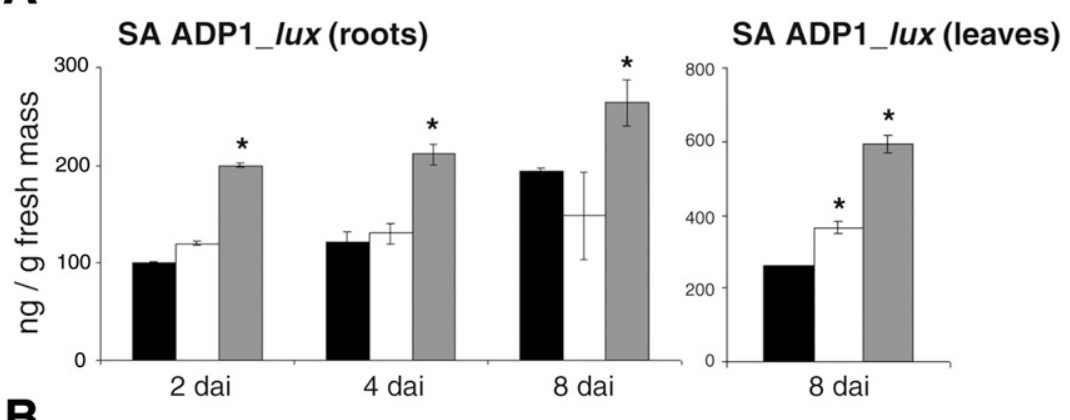

B

SA HPLC (roots)

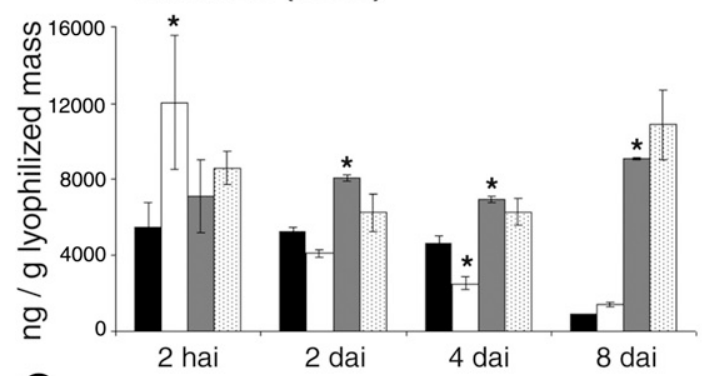

C

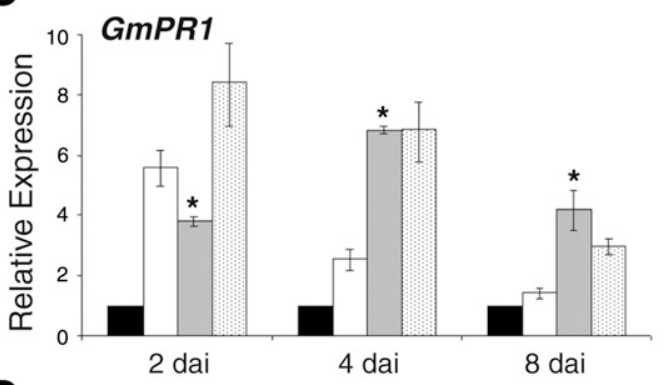

D

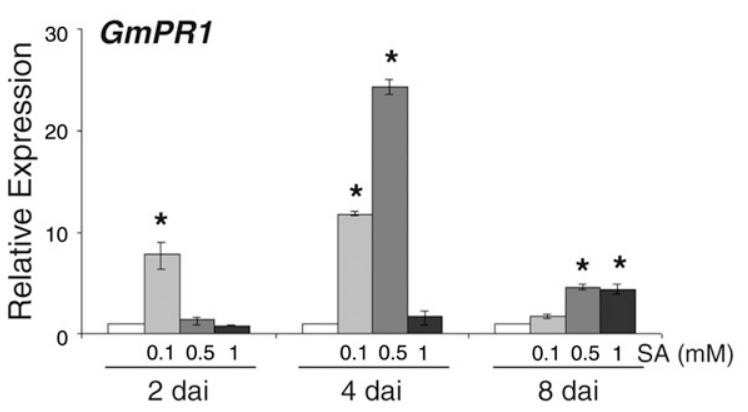

Fig. 2. Expression of the soybean GmPR1 gene correlates with an increase in salicylic acid (SA) concentration in the plant roots. A, Quantification of SA concentration using the biosensor Acinetobacter sp. ADP1_lux in soybean roots and leaves of uninoculated plants (black bars) and inoculated with HH103 Rif ${ }^{\mathrm{R}}$ (white bars) and HH103 Rif ${ }^{\mathrm{R}}$ ttsI $\Omega$ (gray bars). Samples from three independent biological replicates were collected. Data shown are the mean \pm standard deviation (SD) of the mean for three quantifications performed in triplicate for each biological replicate; dai = days after inoculation. B, Quantification by highperformance liquid chromatography (HPLC) of SA concentration in soybean roots of plants grown in plastic containers. Data shown are the mean \pm SD of the mean for three independent biological replicates performed in duplicate. For A and B, HH103 Rif ${ }^{\mathrm{R}}$ and mutant HH103 Rif ${ }^{\mathrm{R}}$ ttsI $\Omega$ were individually compared with the uninoculated control by using the Mann-Whitney nonparametric test. C, Time-course analysis of the expression of the GmPR1 gene in soybean roots. Plants were inoculated with HH103 Rif $^{\mathrm{R}}$ (white bars), HH103 Rif ${ }^{\mathrm{R}}$ ttsI $\Omega$ (gray bars), and HH103 Rif ${ }^{\mathrm{R}}$ ttsI $\Omega$ complemented (dotted bars) and grown in hydroponics systems. Samples from two independent biological replicates were collected. Data shown are the mean \pm SD of the mean for two quantitative polymerase chain reactions (qPCRs) performed in triplicate for each biological replicate. Expression is calculated relative to uninoculated control plants (black bars). The mutant strain HH103 Rif ${ }^{\mathrm{R}} t t s I \Omega$ was individually compared with the parental strain HH103 Rif ${ }^{\mathrm{R}}$ by using the Mann-Whitney nonparametric test. D, Addition of exogenous SA induced the expression of GmPRl in soybean roots. Time-course analysis of the expression of GmPR1 and in the presence of different concentrations of exogenous SA. The expression of the GmPR1 gene was determined by qPCR at 2 dai (light gray bars), 4 dai (gray bars), and 8 dai (dark gray bars). Samples from two independent biological replicates were collected. Data shown are the mean \pm SD of the mean for three quantifications performed in triplicate for each biological replicate. Expression is calculated relative to untreated control plants (black bars). Gene expression at each time point was individually compared with the untreated control by using the Mann-Whitney nonparametric test. For all cases, asterisks indicate that numbers are significantly different at the level $\alpha=5 \%(P<0.05)$. 

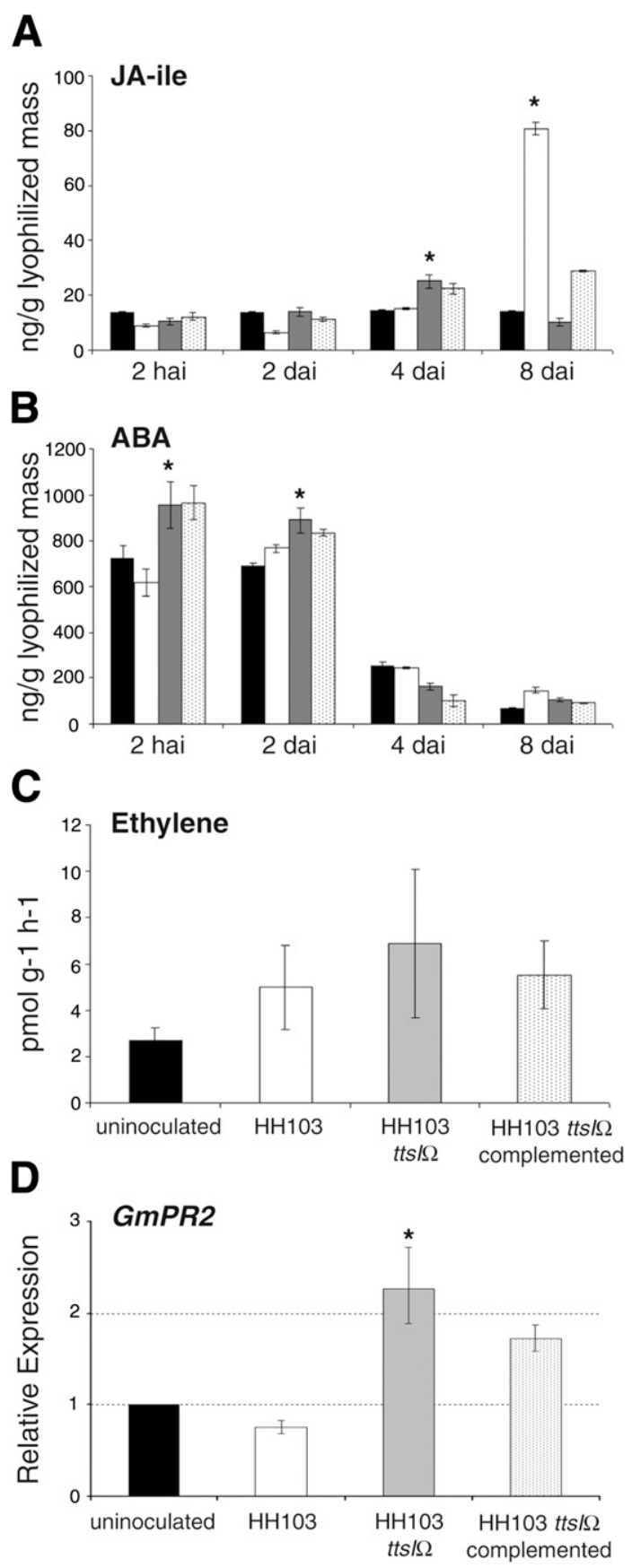

Fig. 3. Quantification of the A, jasmonic acid-isoleucine (JA-ile) and $\mathbf{B}$, abscisic acid (ABA) concentration in soybean roots. Plants were inoculated with HH103 Rif ${ }^{\mathrm{R}}$ (white bars), HH103 Rif $^{\mathrm{R}} t t s I \Omega$ (gray bars), and HH103 $\mathrm{Rif}^{\mathrm{R}} t t s I \Omega$ complemented (dotted bars). Data shown are the mean \pm standard deviation (SD) of the mean for three biological replicates performed in duplicate; hai and dai = hours and days after inoculation, respectively. The parental strain HH103 Rif ${ }^{\mathrm{R}}$ and the mutant strain HH103 Rif $^{\mathrm{R}} t t s I \Omega$ were individually compared with uninoculated control plants (black bars) by using the Mann-Whitney nonparametric test. C, Ethylene produced in soybean roots upon inoculation with several Sinorhizobium fredii HH103 strains. Data shown are the mean \pm SD of the mean for two independent biological replicates. Seven technical replicates were performed for each biological replicate. D, Expression of the GmPR2 gene at 2 dai. Samples from two independent biological replicates were collected. Data shown are the mean $\pm \mathrm{SD}$ of the mean for three quantifications performed in triplicate for each biological replicate. The mutant strain $\mathrm{HH} 103 \mathrm{Rif}^{\mathrm{R}} t t s I \Omega$ was individually compared with the parental strain $\mathrm{HH} 103 \mathrm{Rif}^{\mathrm{R}}$. For all cases, asterisks indicate that numbers are significantly different at the level $\alpha=5 \%$ $(P<0.05)$. fivefold at 8 dai in both cases, but the levels of SA did not substantially change with time in plants inoculated with the mutant strain $t t s I \Omega$ (Fig. 2B).

To confirm that the changes in SA production observed correlated with increases in the transcription of GmPRI (marker for systemic acquired resistance response), the expression of this gene was quantified at different time points. Plants inoculated with HH103 showed the maximum level of expression (approximately sixfold) of the GmPR1 gene at 2 dai. Expression decreased approximately $50 \%$ at 4 dai and finally reached a transcription level similar to the expression observed in control plants at 8 dai (Fig. 2C). In the case of plants inoculated with the $t t s I \Omega$ mutant strain, the peak of highest GmPRl expression (approximately sevenfold) was detected at 4 dai and then the expression slightly declined. In this case, however, the expression of GmPRl was always much higher than the control (Fig. 2C).

Once we confirmed that soybean was reacting to the presence of HH103 and its mutant derivative $t t s I \Omega$ with the production of SA and the expression of $P R$ genes, uninoculated soybean plants were treated with SA to determine whether exogenous addition of this hormone could induce a similar phenotype. First, different SA concentrations $(0.1,0.5$, and $1 \mathrm{mM})$ were tested in the hydroponics system to determine the maximum concentration of SA that does not severely affect soybean growth. Thus, whereas a concentration of $1 \mathrm{mM} \mathrm{SA}$ was highly detrimental for soybean growth (root growth was aborted and necrosis was observed in plant leaves), a concentration of $0.1 \mathrm{mM}$ had no effect. An intermediate phenotype was observed at $0.5 \mathrm{mM}$. Then, the expression of the $G m P R 1$ gene was monitored in SA-treated plants. Results showed that the maximum expression of GmPR1 (24-fold) was also observed at $0.5 \mathrm{mM}$ SA. Interestingly, lower concentrations of exogenous SA induced the expression of GmPRl earlier (2 dai with a concentration of $0.1 \mathrm{mM}, 4$ dai with $0.5 \mathrm{mM}$, and 4 to 8 dai with $1 \mathrm{mM}$ ) (Fig. 2D).

The absence of the $S$. fredii HH103 T3SS affects the production of $\mathrm{JA}$-isoleucine but not the concentration of other hormones such as ABA and ET in soybean roots in the early stages of the symbiotic interaction.

Together with SA, the production of JA-isoleucine (JA-ile) and ABA was quantified at 2 hai and at 2, 4, and 8 dai. JA-ile concentration in soybean roots was similar in all treatments at 2 hai and 2 dai and just slightly increased in plants inoculated with the T3SS mutant strain at 4 dai. However, there was a much clearer peak of JA-ile in roots inoculated with HH103 at 8 dai. By contrast, the concentration of this hormone remained low in uninoculated plants and in plants inoculated with the mutant strain $t t s I \Omega$ (Fig. 3A). No clear differences among treatments were observed in the production of ABA in soybean roots, with the exception of plants inoculated with the T3SS mutant strain, in which a slight increase at 2 hai and 2 dai was observed. Nevertheless, the highest concentrations of this hormone were detected at 2 dai and then dramatically decreased (Fig. 3B).

The production of ET was quantified at 24 hai due to the problems of measuring the concentration of this hormone in soybean roots at more extended times. Results obtained showed an increase in ET production in plants inoculated with HH103 and the $t t s I \Omega$ mutant strain in comparison with uninoculated control plants. A slight but not significant increase in ET production was observed in plants inoculated with the mutant strain in comparison with the production detected in plants inoculated with HH103 (Fig. 3C). The expression of GmPR2, a soybean $P R$ gene whose expression mainly depends on ET but also on SA (Mazarei et al. 2007), was quantified to elucidate 
whether these slight differences in ET production correlated with more significant changes in gene expression. Thus, a significant increase in GmPR2 expression at 2 dai was observed in plants inoculated with the $t t s I \Omega$ strain when compared with the parental strain (Fig. 3D).

\section{The $S$. fredii HH103 T3SS transiently induces} the expression of $G m M P K 4$ in soybean roots.

Plant recognition of MAMP induces the activation of MAPK signal transduction pathways, among other plant responses $(\mathrm{He}$ et al. 2007). To study the activation of MAPK routes, the expression of GmMPK4 was analyzed because it is involved in the negative regulation of SA production and in the modulation of soybean defense responses (Liu et al. 2011). Interestingly, the expression of the GmMPK4 gene was significantly induced at 2 dai in plants inoculated with $\mathrm{HH} 103$ and repressed at 4 dai when plants were inoculated with the $t t s I \Omega$ mutant strain when compared with control plants (Fig. 4A). These differences, however, did not correlate with different amounts of the MPK4 protein, at least in the time points analyzed $(2,4$, and 8 dai; data not shown). Soybean MPK4 negatively regulates the transcription of $G m W R K Y 33$, a transcription factor that activates several genes involved in defense responses (Liu et al. 2011); hence, the expression of this gene was studied to confirm the activation of the signaling cascade. Results obtained showed that the transcription of GmWRKY33 increased fourfold at 8 dai in plants inoculated with the T3SS mutant (Fig. 4B).

\section{DISCUSSION}

Plants interact with a wide range of microorganisms in their natural environments. In the case of legumes, the symbiosis established with rhizobia results in the formation of root nodules where atmospheric nitrogen is fixed. It has been proposed that, in some stages, the symbiotic process resembles a plantpathogen interaction (Soto et al. 2009). However, the fact that nodulation and pathogenesis share components such as the production of reactive oxygen species or plant hormones, among others, gives more complexity to the study of defense responses in a symbiotic context.

Pathogens use different strategies to subvert plant defenses and promote infection, and the T3SS has emerged as an essential weapon to reach this objective. Likewise, the symbiotic T3SS is necessary for an effective nodulation and host-range determination (Deakin and Broughton 2009).

The HH103 T3SS is necessary for an effective nodulation of soybean (López-Baena et al. 2008). To accurately determine the moment at which the inactivation of this secretion system was negatively affecting soybean nodulation, the symbiotic process was monitored during 30 days. Thus, a significant reduction in nodule formation and a delay in the appearance of the first nodules were observed in plants inoculated with the T3SS mutant strain (Fig. 1A). In parallel, the analysis of the expression of the NIN and ENOD4O genes, associated with the development and maintenance of the infection threads and the formation of nodules (Geurts et al. 2005; Marsh et al. 2007), respectively, showed higher levels of transcription in plants inoculated with $\mathrm{HH} 103$ when compared with those inoculated with the T3SS mutant strain (Fig. 1C). These results could point to a partial induction of the expression of these genes by a T3SS-derived signaling and are in agreement with the results shown by Okazaki et al. (2013), who showed that the T3SS can hijack NF signaling and induce the expression of early nodulation genes in soybean, suggesting a role of the T3SS in infections via crack entry or intercellular infection. However, in the case of HH103, NF are essential for nodulation. Interestingly, $\mathrm{HH} 103$ could also induce the formation of nodules in soybean in the presence of extra copies of the T3SS transcriptional regulator $t t s I$ in a nodD1 mutant background, which does not respond to flavonoids and, therefore, cannot synthesize NF and Nops. However, the number of nitrogen-fixing nodules formed was scarce and nodulation was not observed in all inoculated plants (Table 1). All these results would suggest that, although the HH103 T3SS could be inducing the expression of early nodulation genes in the presence of NF under natural conditions, it is unlikely that this contribution clearly affects the final nodule number or that it is the main determinant of the nodulation phenotype observed in soybean plants inoculated with a T3SS mutant.

To elucidate whether the reduction in nodule number was associated with plant immune responses and to study the possible role of the T3SS in the suppression of these mechanisms of defense, the transcriptional regulation of soybean genes and the production of several hormones, both associated with plant defense, were studied.

The first attempts to quantify SA in soybean roots were carried out using the biosensor strain Acinetobacter sp. ADP1_lux, which had been successfully used to quantify SA in tobacco leaves (Huang et al. 2006). The use of this biosensor allowed us to easily discard those treatments that probably will not be affected in the production of SA and select for further analysis and validation using HPLC those in which inoculation with certain

A

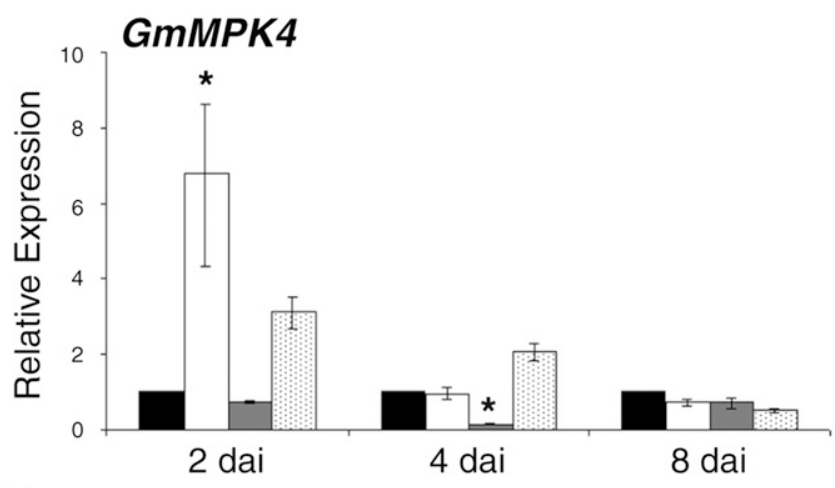

B

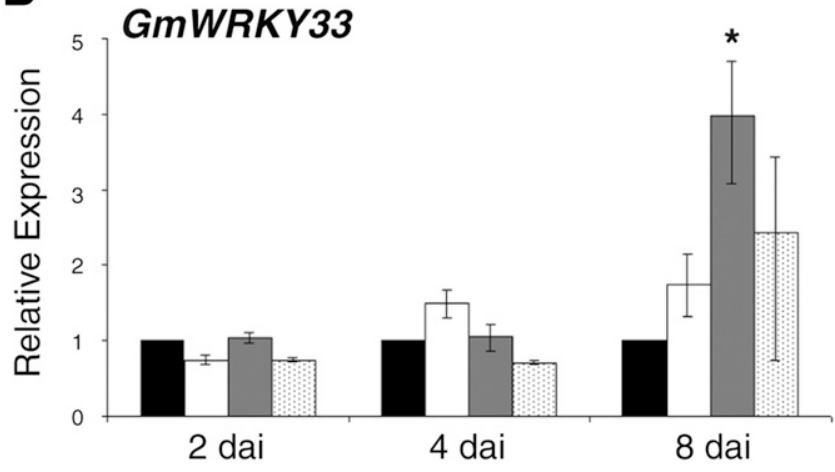

Fig. 4. Inoculation of soybean with Sinorhizobium fredii $\mathrm{HH} 103$ transiently induces the expression of GmMPK4 in roots. Time-course analysis of the expression of A, GmMPK4 and B, GmWRKY33 in soybean roots. Soybean plants were inoculated with HH103 Rif ${ }^{\mathrm{R}}$ (white bars), HH103 $\mathrm{Rif}^{\mathrm{R}}{ }_{t t s I \Omega}$ (gray bars), and HH103 $\mathrm{Rif}^{\mathrm{R}} t t s I \Omega$ complemented (dotted bars); dai = days after inoculation. Samples from two independent biological replicates were collected. Data shown are the mean \pm standard deviation (SD) of the mean for three quantifications performed in triplicate for each biological replicate. Expression is calculated relative to uninoculated control plants (black bars). Mutant HH103 Rif $^{\mathrm{R}} t t s I \Omega$ was individually compared with the parental strain HH103 Rif $^{\mathrm{R}}$ by using the Mann-Whitney nonparametric test. Asterisks indicate that numbers are significantly different at the level $\alpha=$ $5 \%(P<0.05)$. 
HH103 strains caused changes in SA concentration. Quantification of SA in plant roots is time consuming and expensive and requires the analysis of the samples in laboratories specialized in the chemical quantification of this hormone. The protocol described in detail in this work just needs a previous easy extraction of SA and shows that the use of this biosensor could be a useful tool for the determination of SA concentration in root tissues, especially when studying plant-pathogen interactions in which much stronger defense responses are induced. Results obtained using the biosensor showed that the inactivation of $t$ tsI caused an increase in the concentration of SA in soybean roots and leaves when compared with uninoculated control plants and plants inoculated with the parental strain (Fig. 2A), suggesting that the HH103 T3SS was modulating the synthesis of SA. This trend in SA production was confirmed by chemical extraction and analysis of the samples using HPLC (Fig. 2B).

To determine the correlation between SA production and changes in $P R I$ expression in the root, transcription of this gene was quantified at several time points. Thus, GmPR1 showed an early peak of expression in plants inoculated with HH103 and then declined. This GmPRI expression could be related to the early peak of SA production detected at 2 hai, which was not detected in soybean plants inoculated with the $t t s I \Omega$ mutant (Fig. 2B and C). This soybean reaction could be due to the production of an as-yet-unknown MAMP or damage-associated molecular pattern dependent on TtsI. Interestingly, 11 of 18 putative $t t s$ boxes recently identified in the genome of HH103 code for components of the T3SS machinery or proteins secreted through this secretion system, including GunA, which is a cell-wall-degrading enzyme (Vinardell et al. in press). The rest of the putative tts boxes are located in upstream genes whose expression is not regulated by TtsI (J. M. Vinardell, personal communication), discarding them as potential proteins responsible for this soybean reaction. By contrast, plants inoculated with the T3SS mutant strain showed elevated levels of $G m P R l$ expression during the whole experiment but peaked at 4 dai (Fig. 2C).

The addition of exogenous SA to the plant nutrition solution induced a differential expression of GMPRl in soybean roots which depended on SA concentration (Fig. 2D) and also caused a reduction in nodule number (data not shown). These results are in agreement with those in which the addition of SA to soybean roots causes a decrease in nodule number and affects plant growth (Lian et al. 2000) and also with those in which Lotus japonicus NahG transgenic lines with a reduced endogenous SA content have enhanced infection threads formation, root growth, and nodule number (Stacey et al. 2006).

It is known that JA signaling antagonizes SA signaling, and many biotrophic pathogens exploit this property to attenuate host defenses (Glazebrook 2005). A clear peak of JA-ile production that correlated with very low SA concentrations was detected at 8 dai in plants inoculated with $\mathrm{HH} 103$. By contrast,
JA-ile concentration stayed at low levels in those plants inoculated with the T3SS mutant strain (with just a slight increase at 4 dai) while high levels of SA were being produced (Figs. 2B and $3 \mathrm{~A}$ ). The role of JA in nodulation is still not clear. Although some reports suggest that this hormone could act as a negative regulator of nodulation by inhibiting expression of early nodulation genes (Sun et al. 2006), others indicate that this hormone acts as a positive regulator of nodulation (Kinkema and Gresshoff 2008; Seo et al. 2007). In addition, some recent evidence suggests that JA is involved in the autoregulation of nodulation (AON) in soybean (Seo et al. 2007). In this sense, it is remarkable that the peak of JA-ile production in plants inoculated with $\mathrm{HH} 103$ correlated with a reduction in the expression of the early nodulation genes and with the initiation of the AON (Figs. 1B and 3A) (J. E. Ruiz-Sainz, personal communication).

In soybean, homologs of MPK4 negatively regulate defense responses and positively regulate growth and development (Liu et al. 2011). Interestingly, soybean inoculation with HH103 transiently induced the transcription of GmMPK4 in roots at 2 dai but a clear reduction of its expression was detected at 4 dai in plants inoculated with a T3SS mutant strain (Fig. 4A). This differential gene expression correlated with changes in SA production and GmPRl gene expression (Fig. 2B and C). Most MAPK are regulated trough phosphorylation activation. Others, such as the tobacco wound-induced protein kinase (WIPK), are induced at the transcriptional level in response to stress stimuli and pathogen attack. Thus, maximum levels of expression of WIPK are reached in the first 24 hai with a plant pathogen (Seo et al. 1995; Zhang and Klessig 1998; Zhang et al. 2000). However, the exact moment in which HH103 is detected by plant defense mechanisms is not defined yet, although some results also point to a recognition that occurs during the initial stages of the symbiosis and not once the symbiosis has been established (López-Gómez et al. 2012).

WRKY transcription factors positively and negatively regulate defense responses. In the case of WRKY33, active MPK4 phosphorylates MKS1 and leads to the release of WRKY33 in the nucleus. Free WRKY33 is then supposed to be responsible for transcriptional activation of downstream genes by binding to W-boxes (Qiu et al. 2008). Our results suggest that not only is WRKY33 as well as MPK4 function regulated at the cellular level but also the HH103 T3SS regulates its activity at the transcriptional level.

Interestingly, a drastic interruption in the growth of the main root of soybean plants inoculated with the T3SS mutant strain was observed, and there was an apparent reduction in root development compared with untreated roots (Fig. 2B). This phenotype is typically associated with plant defense responses and could be explained by the overproduction of two hormones: (i) ET, which causes a reduction in root development and thickening of the hypocotyl (Hoffman et al. 1999); or (ii) $\mathrm{SA}$, which is associated with dwarfism and stunted growth

Table 1. Overexpression of the Sinorhizobium fredii HH103 ttsI gene induces the formation of nodules in Glycine max Williams 82 in the absence of NodD1 ${ }^{\text {a }}$

\begin{tabular}{|c|c|c|c|c|c|c|}
\hline \multirow[b]{2}{*}{ Inoculant } & \multicolumn{3}{|c|}{ Test 1} & \multicolumn{3}{|c|}{ Test 2} \\
\hline & Plants tested & Nodulated plants & $\begin{array}{c}\text { Nodules per } \\
\text { nodulated plant }\end{array}$ & Plants tested & Nodulated plants & $\begin{array}{c}\text { Nodules per } \\
\text { nodulated plant }\end{array}$ \\
\hline None & 6 & 0 & 0 & 6 & 0 & 0 \\
\hline HH103 Rif $^{\mathrm{R}}$ & 6 & 6 & $46.3 \pm 19.8$ & 10 & 10 & $52.1 \pm 12.6$ \\
\hline $\mathrm{HH} 103 \mathrm{Rif}^{\mathrm{R}} \operatorname{nod} \mathrm{D} 1 \Omega$ & 6 & 0 & 0 & 6 & 0 & 0 \\
\hline 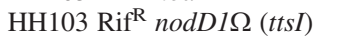 & 6 & 4 & $4.25 \pm 2.06^{*}$ & 10 & 4 & $6.5 \pm 7.4^{*}$ \\
\hline HH103 Rif ${ }^{\mathrm{R}}$ nodA::Tn5-lacZ & 6 & 0 & 0 & 6 & 0 & 0 \\
\hline HH103 $\operatorname{Rif}^{\mathrm{R}}(t t s I)$ & 6 & 6 & $63.83 \pm 20.62$ & 10 & 10 & $61.16 \pm 17.03$ \\
\hline
\end{tabular}

a Nodules fixed nitrogen, as demonstrated by acetylene reduction assay. Bacteria isolated from nodules showed the expected resistance markers. 
(Liu et al. 2011). No significant differences were observed in the production of ET between plants inoculated with the T3SS mutant strain and those inoculated with the parental strain, suggesting that this impairment in root growth is more likely to be due to higher levels of SA in the roots.

Complementation of the mutation in the ttsI gene, which restores the capacity of the mutant to secrete Nops, was successfully performed using the high-copy plasmid pMP92 (due to problems for complementation using other approaches) for in vitro experiments and nodulation assays (López-Baena et al. 2008, 2009). However, for plant gene expression time-course assays and hormones quantification, results are sometimes not so clear. This is because it was not possible to control the gene dose and the stability of the plasmid during the whole symbiotic process.

In summary, results shown in this work would indicate that soybean reacts to the presence of a still-unknown molecule produced by $\mathrm{HH} 103$, triggering a defense response, mainly mediated by SA, that is promptly suppressed by the T3SS. In the absence of a functional T3SS, this defense reaction, initially localized to the root, becomes systemic. Results obtained would also highlight the importance of controlling the levels of endogenous SA for an efficient nodulation and strengthen the idea that rhizobia have developed different mechanisms to inhibit SA production and suppress SA-related defense responses. In this sense, it is known that many pathogens can hijack host hormone biosynthetic or signaling pathways to overcome innate immunity and modulate host metabolism for their benefit (Robert-Seilaniantz et al. 2011).

To date, defense responses in the symbiotic rhizobia-legume interactions have been described as weak and transitory. However, in this work, we show that rhizobia can also initially be recognized by plant defense mechanisms and trigger a response strong enough to block nodulation (e.g., symbiosis $S$. fredii USDA257-American soybeans) or significantly reduce nodulation efficiency (e.g., symbiosis S. fredii HH103soybean). Our results suggest that $\mathrm{HH} 103$ has developed strategies, such as the T3SS, to suppress soybean early defense responses and promote nodulation. It would be possible that this capacity to suppress or diminish early host defense responses allows broad-host-range rhizobia to induce the formation of nodules in a high number of different legumes. Therefore, efforts are necessary to determine which plant host proteins are the targets of the effectors in order to identify plant processes and mechanisms that potentially could be involved not only in the elicitation of defense responses but also in the initiation and development of the root nodule.

\section{MATERIALS AND METHODS}

\section{Microbial techniques.}

Bacterial strains and plasmids are listed in Supplementary Table S1. Ensifer (Sinorhizobium) fredii strains were grown at $28^{\circ} \mathrm{C}$ on yeast extract mannitol medium (Vincent 1970). Acinetobacter sp. ADPWH_lux and Escherichia coli strains were cultured on Luria-Bertani (LB) medium at 28 or $37^{\circ} \mathrm{C}$. When required, the media were supplemented with the antibiotics rifampicin and spectinomycin $\left(50 \mu \mathrm{g} \mathrm{ml}{ }^{-1}\right)$ and tetracycline $\left(2 \mu \mathrm{g} \mathrm{ml}^{-1}\right.$ for rhizobia or $10 \mu \mathrm{g} \mathrm{ml}^{-1}$ for E. coli). Conjugations were performed as described by Simon (1984).

\section{Plant growth conditions.}

Glycine $\max (\mathrm{L}$.$) Merrill Williams82 plants were grown$ under the following conditions. (i) Plastic containers ( 30 by 25 by $25 \mathrm{~cm}$ ) filled with vermiculite (20 plants per container) and irrigated with Fåhraeus solution (Vincent 1970). Each plant was inoculated with $1 \mathrm{ml}$ of bacterial culture at an optical density at
$600 \mathrm{~nm}\left(\mathrm{OD}_{600}\right)=0.5$ (approximately $10^{8}$ bacteria $\mathrm{ml}^{-1}$ ). (ii) The hydroponics system previously described by López-Baena et al. (2009) containing 10 plants. When necessary, different SA concentrations were added to the plant nutrition solution. The transferred pregerminated seed were inoculated with approximately $10^{8}$ bacteria $\mathrm{ml}^{-1}$. (iii) Leonard jars containing two soybean plants and following the methodology previously described (de Lyra et al. 2006). Each plant was inoculated with $1 \mathrm{ml}$ of bacterial culture at an $\mathrm{OD}_{600}=0.5$. Growth conditions were set to a cycle of 16 and $8 \mathrm{~h}$, day $\left(26^{\circ} \mathrm{C}\right)$ and night $\left(18^{\circ} \mathrm{C}\right)$, respectively and a relative humidity of $70 \%$. For the nodulation kinetics assay, soybean plants were grown in Leonard jars and nodules were counted $8,12,16,24$, and 30 dai.

\section{RNA isolation, cDNA synthesis, and}

quantitative polymerase chain reaction analysis.

RNA extraction and cDNA synthesis were performed as described by López-Baena et al. (2009). RNA concentration was quantified using a Nanodrop 2000 spectrophotometer (Thermo Scientific, U.S.A.).

To quantify soybean gene expression, gene-specific primer pairs were employed (Supplementary Table S2). Expression was calculated relative to uninoculated control plants. The $U B I 3$ gene was used as an internal control to normalize gene expression across different samples. The ELF1 $\beta$ gene was also used as an internal control, only to confirm results. The fold change in the target gene, normalized to RNA UBI3 and relative to the gene expression in the control sample, was calculated.

Each reaction was performed in a $10-\mu$ final volume containing $25 \mathrm{ng}$ of cDNA, $0.6 \mathrm{pmol}$ of each primer, and $10 \mu \mathrm{l}$ of FastStart SYBR Green Master Mix (Roche, Switzerland). Polymerase chain reaction was conducted on the Light Cycler 480 II (Roche, Switzerland) with the following conditions: $95^{\circ} \mathrm{C}$ for $10 \mathrm{~min} ; 45$ cycles of $95^{\circ} \mathrm{C}$ for $30 \mathrm{~s}, 52^{\circ} \mathrm{C}$ for $30 \mathrm{~s}$, and $72^{\circ} \mathrm{C}$ for $15 \mathrm{~s}$; followed by the melting curve profile from 65 to $95^{\circ} \mathrm{C}$ to verify the specificity of the reaction. The threshold cycles were determined with the Light Cycler 480 II software (Roche) and the individual values for each sample were generated by averaging three technical replicates that varied less than 0.5 cycles.

\section{SA extraction and detection in soybean roots using the biosensor Acinetobacter sp. ADP1_lux.}

The procedure to obtain crude extracts for SA detection was adapted from Bowling et al. (1994) and Enyedi et al. (1992). Thus, $0.2 \mathrm{~g}$ of frozen soybean roots was extracted in $2 \mathrm{ml}$ of a 90:10 methanol/water solution, sonicated for $30 \mathrm{~min}$ at room temperature, and incubated overnight at $-20^{\circ} \mathrm{C}$. After another sonication for $30 \mathrm{~min}$, the sample was centrifuged at $12,000 \mathrm{rpm}$ for $15 \mathrm{~min}$. The supernatant was recovered and evaporated under vacuum in a centrifuge concentrator at $40^{\circ} \mathrm{C}$ (Heto Holten Ltd., U.K.). The dried residue was resuspended in a $0.1 \mathrm{M}$ sodium acetate solution $(\mathrm{pH} 4.5)$ and incubated overnight at $37^{\circ} \mathrm{C}$. Acidified ethyl acetate was then added and the mixture was centrifuged at $12,000 \mathrm{rpm}$ for $3 \mathrm{~min}$. The top layer was recovered and evaporated under vacuum in a centrifuge concentrator at room temperature. Finally, the pellet was resuspended in a 50:50 methanol/water solution and the methanol was evaporated.

Detection of SA was performed following the methodology described by DeFraia et al. (2008), with some modifications. An overnight culture of the biosensor Acinetobacter sp. $A D P W H \_l u x$ was diluted in $100 \mathrm{ml}$ of LB medium and incubated at $37^{\circ} \mathrm{C}$ to an $\mathrm{OD}_{600}$ of exactly 0.3 . Bacterial culture $(100 \mu \mathrm{l})$ was mixed with $50 \mu \mathrm{l}$ of the sample and $50 \mu \mathrm{l}$ of a $10 \mathrm{mM} \mathrm{MgCl} 2$ solution in a 96-well black cell culture plate (Vision Plate 96; 4titude, U.K.). The plate was incubated for $1 \mathrm{~h}$ 
at room temperature before luminescence was read using a microtiter automatic reader (Synergy HT; BioTek, U.S.A.).

A calibration curve was obtained using known concentrations of commercial SA. SA standards were read in parallel with the experimental samples. The average values of the pattern without SA were subtracted from the values obtained from the different treatments. Conversion of luminescence to SA concentration was done using the slope of the curve. SA concentration was obtained using the equation $n g \mathrm{SA} \mathrm{g}^{-1}$ dry mass = $\mathrm{A} \times \mathrm{B} \times \mathrm{C} \times \mathrm{DF}$, where $\mathrm{A}=$ the molar value obtained under the experimental conditions $\left(\mu \mathrm{M} \mathrm{SA} \times 10^{-6}\right) ; \mathrm{B}=\left(50 \times 10^{-6}\right)$, which is the volume of the sample expressed in liters; $\mathrm{C}=$ $138.12 \times 10^{9}$, which is the molecular mass of SA (ng); and DF = dilution factor $=[$ well volume $(200 \mu \mathrm{l}) /$ sample volume $(50 \mu \mathrm{l})] \times$ [total volume SA extraction in the Eppendorf tube $(150 \mu \mathrm{l}) /$ sample volume $(50 \mu \mathrm{l})] \times(1 \mathrm{~g}$ of soybean root dry mass $/ 0.2 \mathrm{~g}$ used for SA extraction) (Supplementary Fig. S1).

\section{SA, JA-ile, and ABA extraction and detection using HPLC.}

Fresh soybean roots were frozen in liquid nitrogen, ground to a fine powder, and lyophilized. Then, $0.5 \mathrm{~g}$ was extracted in $5 \mathrm{ml}$ of distilled water after spiking with $50 \mu \mathrm{l}$ of a mixture of internal standards containing $100 \mathrm{ng}$ of $\left[{ }^{2} \mathrm{H}_{6}\right] \mathrm{ABA},\left[{ }^{2} \mathrm{H}_{4}\right] \mathrm{SA}$, $\left[{ }^{2} \mathrm{H}_{2}\right]$ JA-Ile, and dihydro jasmonic acid. After centrifugation at $4,000 \times g$ at $4^{\circ} \mathrm{C}$, supernatants were recovered and the $\mathrm{pH}$ adjusted to 3.0 with $30 \%$ acetic acid. The acidified water extract was partitioned twice against $3 \mathrm{ml}$ of di-ethyl ether. The organic upper layer was recovered and evaporated under vacuum in a centrifuge concentrator (Speed Vac, Jouan, France). The dry residue was then resuspended in a $10 \%$ methanol solution by gentle sonication. The resulting solution was filtered through regenerated cellulose $0.22-\mu \mathrm{m}$ membrane syringe filters (Albet S.A., Spain) and directly injected into the HPLC system.

Ultra-HPLC was performed using a Waters (Milford, U.S.A.) Alliance 2690 system, which consists of an autosampler and a quaternary pump. Aliquots $(20 \mu \mathrm{l})$ were injected in a Nucleosil ODS reversed-phase column (50 by $2 \mathrm{~mm}$ i.d., $1.8 \mu \mathrm{m}$; Scharlab, Spain). Phytohormones were eluted with a gradient of methanol and $0.01 \%$ ( $\mathrm{vol} / \mathrm{vol})$ acetic acid in water that started from 10:90 (vol/vol) for $2 \mathrm{~min}$. In the following $4 \mathrm{~min}$, the gradient increased to $10: 90$ ( $\mathrm{vol} / \mathrm{vol})$. Isocratic conditions of 10:90 were retained during the last $2 \mathrm{~min}$ of the run. The initial conditions were restored and allowed to equilibrate for $3 \mathrm{~min}$, giving a total time of $10 \mathrm{~min}$ per sample. The solvent flow rate was $0.3 \mathrm{ml} \mathrm{min} \mathrm{m}^{-1}$, with working pressures of approximately 211 to 220 bar.

The effluents from the HPLC were introduced into a triplequadrupole mass spectrometer (Micromass, U.K.) using an orthogonal Z-spray electrospray interface (Micromass). Nitrogen was used as drying and nebulizing gas. For operation in the tandem mass spectrometry mode, the collision gas was 99.995\% pure argon (Carburos Metálicos, Spain) with a pressure of $2 \times 10^{-3}$ mbar in the collision cell. The desolvation gas temperature was $350^{\circ} \mathrm{C}$, the source temperature $120^{\circ} \mathrm{C}$, and the capillary voltage was $-3 \mathrm{kV}$. The mass spectrometer was operated in multiple reaction monitoring mode. The cone voltage and collision energies are summarized in Supplementary Table S3. Masslynx NT software (version 4.0; Micromass) was used to process the chromatograms.

\section{Western blot assays.}

Total proteins from soybean plants inoculated with of $S$. fredii HH103Rif ${ }^{\mathrm{R}}$, HH103Rif ${ }^{\mathrm{R}} t t s I \Omega$, and the complemented strain were extracted following the protocol described by Monreal et al. (2013). For immunostaining, proteins were separated on sodium dodecyl sulfate-12\% (mass/volume) polyacrylamide gels and electroblotted to polyvinylidene difluoride membranes using a Mini Trans-Blot electrophoretic transfer cell (Bio-Rad, U.S.A.). Membranes were blocked with Tris-buffered saline containing $2 \%(\mathrm{~m} / \mathrm{v})$ bovine serum albumen and then incubated with antibodies raised against AtMAPK4 (Sigma-Aldrich, Germany) diluted 1:1000 in the same solution. Antirabbit immunoglobulin antibodies (hrp-linked) were used as secondary antibodies. Reaction results were visualized using a LAS3000 intensified CCD camera (Fujifilm, Japan) and images were analyzed with the Image Reader LAS3000 software.

\section{ET production.}

ET biosynthesis was assayed by placing two 2-day-old soybean seedlings in 15-ml tubes. Seedlings were inoculated by dipping in the different rhizobial cultures $\left(\mathrm{OD}_{600}=0.5\right)$ for 5 min. Tubes were sealed with rubber caps, and ET accumulating in the headspace within $24 \mathrm{~h}$ of incubation was determined by gas chromatography.

\section{ACKNOWLEDGMENTS}

We thank the Junta de Andalucía (project P11-CVI-7050), the Ministerio de Economía y Competitividad (project AGL2012-38831), and V Plan Propio de Investigación de la Universidad de Sevilla (VPPI-US) for funding this work, and the Servicio de Biología of the CITIUS (Universidad de Sevilla) for their technical support.

\section{LITERATURE CITED}

Alfano, J. R., and Collmer, A. 2004. Type III secretion system effector proteins: Double agents in bacterial disease and plant defense. Annu. Rev. Phytopathol. 42:385-414.

Boller, T., and Felix, G. 2009. A renaissance of elicitors: Perception of microbe-associated molecular patterns and danger signals by patternrecognition receptors. Annu. Rev. Plant Biol. 60:379-406.

Bowling, S. A., Guo, A., Cao, H., Gordon, A. S., Klessig, D. F., and Dong, X. 1994. A mutation in Arabidopsis that leads to constitutive expression of systemic acquired resistance. Plant Cell 6:1845-1857.

Deakin, W. J., and Broughton, W. J. 2009. Symbiotic use of pathogenic strategies: Rhizobial protein secretion systems. Nat. Rev. Microbiol. 7:312-320.

DeFraia, C., Schmelz, E. A., and Mou, Z. 2008. A rapid biosensor-based method for quantification of free and glucose-conjugated salicylic acid. Plant Methods 4:28-39.

de Lyra, M. C. C. P., López-Baena, F. J., Madinabeitia, N., Vinardell, J. M., Espuny, M. R., Cubo, M. T., Bellogín, R. A., Ruiz-Sainz, J. E., and Ollero, F. J. 2006. Inactivation of the Sinorhizobium fredii $\mathrm{HH} 103$ rhcJ gene abolishes nodulation outer proteins (Nops) secretion and decreases the symbiotic capacity with soybean. Int. Microbiol. 9:125-133.

Downie, J. A. 2010. The roles of extracellular proteins, polysaccharides and signals in the interactions of rhizobia with legume roots. FEMS Microbiol. Rev. 34:150-170.

Enyedi, A. J., Yalpani, N., Silverman, P., and Raskin, I. 1992. Signal molecules in systemic plant resistance to pathogens and pests. Proc. Natl. Acad. Sci. U.S.A. 89:2480-2484.

Geurts, R., Fedorova, E., and Bisseling, T. 2005. Nod factor signaling genes and their function in the early stages of Rhizobium infection. Curr. Opin. Plant Biol. 8:346-352.

Glazebrook, J. 2005. Contrasting mechanisms of defense against biotrophic and necrotrophic pathogens. Annu. Rev. Phytopathol. 43:205-227.

Grant, M. R., and Jones, J. D. G. 2009. Hormone (dis)harmony moulds plant health and disease. Science 324:750-752.

Hayashi, M., Saeki, Y., Haga, M., Harada, K., Kouchi, H., and Umehara, Y. 2012. $R j$ ( $r j$ ) genes involved in nitrogen-fixing root nodule formation in soybean. Breed. Sci. 61:544-553.

He, P., Shan, L., and Sheen, J. 2007. Elicitation and suppression of microbeassociated molecular pattern-triggered immunity in plant-microbe interactions. Cell. Microbiol. 9:1385-1396.

Hoffman, T., Schmidt, J. S., Zheng, X., and Bent, A. F. 1999. Isolation of ethylene-insensitive soybean mutants that are altered in pathogen susceptibility and gene-for-gene disease resistance. Plant Physiol. 119:935-950.

Huang, W. E., Huang, L., Preston, G. M., Martin, N., Carr, J. P., Yanhong, L., Singer, A. C., Whiteley, A. S., and Hui, W. 2006. Quantitative in situ assay of salicylic acid in tobacco leaves using a genetically modified biosensor strain of Acinetobacter sp. ADP1. Plant J. 46:1073-1083. 
Jones, J. D., and Dangl, J. L. 2006. The plant immune system. Nature 444: 323-329.

Kinkema, M., and Gresshoff, P. M. 2008. Investigation of downstream signals of the soybean autoregulation of nodulation receptor kinase GmNARK. Mol. Plant-Microbe Interact. 21:1337-1348.

Kunkel, B. N., and Brooks, D. M. 2002. Cross talk between signaling pathways in pathogen defense. Curr. Opin. Plant Biol. 5:325-331.

Lian, B., Zhou, X., Miransari, M., and Smith, D. L. 2000. Effects of salicylic acid on the development and root nodulation of soybean seedlings. J. Agron. Crop Sci. 185:187-192.

Liu, J. Z., Horstman, H. D., Braun, E., Graham, M. A., Zhang, C., Navarre, D., Qiu, W. L., Lee, Y., Nettleton, D., Hill, J. H., and Whitham, S. A. 2011. Soybean homologues of MPK4 negatively regulate defense responses and positively regulate growth and development. Plant Physiol. 157: 1363-1378.

Liu, J. Z., Braun, E., Qiu, W. L., Shi, Y. F., Marcelino-Guimarães, F. C., Navarre, D., Hill, J. H., and Whitham, S. A. 2014. Positive and negative roles for soybean MPK6 in regulating defense responses. Mol. PlantMicrobe Interact. 27:1172.

López-Baena, F. J., Monreal, J. A., Pérez-Montaño, F., Guasch-Vidal, B. Bellogín, R. A., Vinardell, J. M., and Ollero, F. J. 2009. The absence of Nops secretion in Sinorhizobium fredii HH103 increases GmPRI expression in Williams soybean. Mol. Plant-Microbe Interact. 22: 1445-1454.

López-Baena, F. J., Vinardell, J. M., Pérez-Montaño, F., Crespo-Rivas, J. C., Bellogín, R. A., Espuny, M. R., and Ollero, F. J. 2008. Regulation and symbiotic significance of nodulation outer proteins secretion in Sinorhizobium fredii HH103. Microbiology 154:1825-1836.

López-Gómez, M., Sandal, N., Stougaard, J., and Boller, T. 2012. Interplay of flg22-induced defence responses and nodulation in Lotus japonicus. J. Exp. Bot. 63:393-401.

Margaret, I., Becker, A., Blom, J., Bonilla, I., Goesmann, A., Göttfert, M., Lloret, J., Mittard-Runte, V., Rückert, C., Ruiz-Sainz, J. E., Vinardell, J. M., and Weidner, S. 2011. Symbiotic properties and first analyses of the genomic sequence of the fast growing model strain Sinorhizobium fredii $\mathrm{HH} 103$ nodulating soybean. J. Biotechnol. 155:11-19.

Marsh, J. F., Rakocevic, A., Mitra, R. M., Brocard, L., Sun, J., Eschstruth, A. Long, S. R., Schultze, M., Ratet, P., and Oldroyd, F. E. D. 2007. Medicago truncatula NIN is essential for rhizobial-independent nodule organogenesis induced by autoactive calcium/calmodulin-dependent protein kinase. Plant Physiol. 144:324-335.

Mazarei, M., Elling, A. A., Maier, T. R., Puthoff, D. P., and Baum, T. J. 2007. GmEREBP1 is a transcription factor activating defense genes in soybean and Arabidopsis. Mol. Plant-Microbe Interact. 20:107-119.

Meinhardt, L. W., Krishnan, H. B., Balatti, P. A., and Pueppke, S. G. 1993. Molecular cloning and characterization of a sym plasmid locus that regulates cultivar-specific nodulation of soybean by Rhizobium fredii USDA257. Mol. Microbiol. 9:17-29.

Meng, X., and Zhang, S. 2013. MAPK cascades in plant disease resistance signaling. Annu. Rev. Phytopathol. 51:245-266.

Monreal, J. A., Arias-Baldrich, C., Pérez-Montaño, F., Gandullo, J., Echevarría, C., and García-Mauriño, S. 2013. Factors involved in the raise of phosphoenolpyruvate carboxylase-kinase activity caused by salinity in sorghum leaves. Planta 237:1401-1413.

Okazaki, S., Kaneko, T., Sato, S., and Saeki, K. 2013. Hijacking of leguminous nodulation signaling by the rhizobial type III secretion system. Proc. Natl. Acad. Sci. U.S.A. 110:17131-17136.

Okazaki, S., Okabe, S., Higashi, M., Shimoda, Y., Sato, S., Tabata, S. Hashiguchi, M., Akashi, R., Göttfert, M., and Saeki, K. 2010. Identification and functional analysis of type III effector proteins in Mesorhizobium loti. Mol. Plant-Microbe Interact. 23:223-234.

Pieterse, C. M., Leon-Reyes, A., Van der Ent, S., and Van Wees, S. C. 2009. Networking by small-molecule hormones in plant immunity. Nat. Chem. Biol. 5:308-316.

Qiu, J. L., Fiil, B. K., Petersen, K., Nielsen, H. B., Botanga, C. J., Thorgrimsen, S., Palma, K., Suarez-Rodriguez, M. C., Sandbech-Clausen,
S., Lichota, J., Brodersen, P., Grasser, K. D., Mattsson, O., Glazebrook, J., Mundy, J., and Petersen, M. 2008. Arabidopsis MAP kinase 4 regulates gene expression through transcription factor release in the nucleus. EMBO J. 27:2214-2221.

Robert-Seilaniantz, A., Grant, M., and Jones, J. D. 2011. Hormone crosstalk in plant disease and defense: More than just jasmonate-salicylate antagonism. Annu. Rev. Phytopathol. 49:317-343.

Sánchez, C., Mercante, V., Babuin, M. F., and Lepek, V. C. 2012. Dual effect of Mesorhizobium loti T3SS functionality on the symbiotic process. FEMS Microbiol. Lett. 330:148-156.

Seo, H. S., Li, J., Lee, S. Y., Yu, J. W., Kim, K. H., Lee, S. H., Lee, I. J., and Paek, N. C. 2007. The hypernodulating nts mutation induces jasmonate synthetic pathway in soybean. Mol. Cell 24:185-193.

Seo, S., Okamoto, M., Seto, H., Ishizuka, K., Sano, H., and Ohashi, Y. 1995. Tobacco MAP kinase: A possible mediator in wound signal transduction pathways. Science 270:1988-1992.

Simon, R. 1984. High frequency mobilization of gram-negative bacterial replicons by the in vivo constructed Tn5-Mob transposon. Mol. Gen. Genet. 196:413-420.

Soto, M. J., Domínguez-Ferreras, A., Pérez-Mendoza, D., Sanjuán, J., and Olivares, J. 2009. Mutualism versus pathogenesis: The give-and-take in plant-bacteria interactions. Cell. Microbiol. 11:381-388.

Stacey, G., McAlvin, C. B., Kim, S. Y., Olivares, J., and Soto, M. J. 2006. Effects of endogenous salicylic acid on nodulation in the model legumes Lotus japonicus and Medicago truncatula. Plant Physiol. 141:1473-1481.

Sun, J., Cardoza, V., Mitchell, D. M., Bright, L., Oldroyd, G., and Harris, J. M. 2006. Crosstalk between jasmonic acid, ethylene and Nod factor signaling allows integration of diverse inputs for regulation of nodulation. Plant J. 46:961-970.

Tsuda, K., and Katagiri, F. 2010. Comparing signaling mechanisms engaged in pattern-triggered and effector-triggered immunity. Curr. Opin. Plant Biol. 13:459-465

Tsukui, T., Eda, S., Kaneko, T., Sato, S., Okazaki, S., Kakizaki-Chiba, K., Itakura, M., Mitsui, H., Yamashita, A., Terasawa, K., and Minamisawa, K. 2013. The type III secretion system of Bradyrhizobium japonicum USDA122 mediates symbiotic incompatibility with Rj2 soybean plants. Appl. Environ. Microbiol. 79:1048-1051.

Vasse, J., de Billy, F., and Truchet, G. 1993. Abortion of infection during the Rhizobium meliloti-alfalfa symbiotic interaction is accomplished by a hypersensitive reaction. Plant J. 4:555-566.

Vinardell, J. M., Acosta-Jurado, S., Göttfert, M., Zehner, S., Becker, A., Baena-Ropero, I., Blom, J., Crespo-Rivas, J. C., Goesmann, A., Jaenicke, S., Krol, E., McIntosh, M., Margaret, I., Pérez-Montaño, F. Schneiker-Bekel, S., Serrania, J., Szczepanowski, R., Buendia-Claveria, A. M., Lloret, J., Bonilla, I., Pühler, A., Ruiz-Sainz, J. E., and Weidner, S. The Sinorhizobium fredii HH103 genome: A comparative analysis with $S$. fredii strains differing in their symbiotic behaviour with soybean. Mol. Plant-Microbe Interact. In press.

Vincent, J. M. 1970. Appendix III. The modified Fåhraeus slide technique. Pages 144-155 in: A Manual for the Practical Study of Root Nodule Bacteria. J. M. Vincent, ed. Blackwell Scientific Publications, Oxford.

Xin, D. W., Liao, S., Xie, Z. P., Hann, D. R., Steinle, L., Boller, T., and Staehelin, C. 2012. Functional analysis of NopM, a novel E3 ubiquitin ligase (NEL) domain effector of Rhizobium sp. strain NGR234. PLoS Pathog. 8:e1002707.

Yang, S., Tang, F., Gao, M., Krishnan, H. B., and Zhu, H. 2010. $R$ genecontrolled host specificity in the legume-rhizobia symbiosis. Proc. Natl Acad. Sci. U.S.A. 107:18735-18740.

Zamioudis, C., and Pieterse, C. M. J. 2012. Modulation of host immunity by beneficial microbes. Mol. Plant-Microbe Interact. 25:139-150.

Zhang, S., and Klessig, D. F. 1998. The tobacco wounding-activated mitogen-activated protein kinase is encoded by SIPK. Proc. Natl. Acad. Sci. U.S.A. 95:7225-7230.

Zhang, S., Liu, Y., and Klessig, D. F. 2000. Multiple levels of tobacco WIPK activation during the induction of cell death by fungal elicitins. Plant J. 23:339-347. 